\title{
Serum Micronutrient Status of Haart-Naïve, HIV Infected Children in South Western Nigeria: A Case Controlled Study
}

\author{
H. C. Anyabolu, E. A. Adejuyigbe, and O. O. Adeodu \\ Department of Paediatrics and Child Health, Obafemi Awolowo University, Private Mail Bag 13, ILE-IFE, Nigeria \\ Correspondence should be addressed to H. C. Anyabolu; henrypaediatrics@yahoo.com
}

Received 3 February 2014; Revised 22 June 2014; Accepted 22 July 2014; Published 11 August 2014

Academic Editor: Soraya Seedat

Copyright ( 2014 H. C. Anyabolu et al. This is an open access article distributed under the Creative Commons Attribution License, which permits unrestricted use, distribution, and reproduction in any medium, provided the original work is properly cited.

\begin{abstract}
Background. Though micronutrients are vital in the pathogenesis of human immunodeficiency virus infection, most studies have been conducted in adults. Knowledge of the status of key micronutrients in HIV infected African children will indicate if supplementation may be beneficial to these children living in this resource-poor region. Objectives. We sought to determine the micronutrient status and associated factors of HAART-naïve HIV infected children and compare them with those of the HIV negative controls. Methods. We enrolled 70 apparently stable HAART naïve HIV infected children. Seventy age and sex matched HIV negative children were equally enrolled as the controls. Their social class, anthropometry, clinical stage, CD4 counts, serum zinc, selenium, and vitamin C were determined. Results. The prevalence of zinc, selenium, and vitamin C deficiency in HIV infected subjects was $77.1 \%, 71.4 \%$, and $70.0 \%$, respectively, as compared to $44.3 \%, 18.6 \%$, and $15.7 \%$ in HIV negative controls. Among the HIV infected subjects, $58.6 \%$ were deficient in the three micronutrients. Micronutrient status was related to the weight, clinical, and immunological stages but not BMI or social class. Conclusion. Deficiency of these key micronutrients is widely prevalent in HAART naïve HIV infected children irrespective of social class. This suggests that supplementation trial studies may be indicated in this population.
\end{abstract}

\section{Introduction}

With an estimated 321,000 children living with the human immunodeficiency virus (HIV) in Nigeria as at 2010, it is currently established that the country has the largest burden of paediatric HIV infection in the world [1]. HIV infection has been associated with low selenium status in Western nations [2] and Nigeria [3]. The utilization of host selenium by HIV to form selenoproteins essential for viral replication has been postulated as contributory to the low selenium level [2]. In a prospective cohort study of 670 children born to HIVinfected women, low plasma selenium levels were associated with an increased risk of mortality [4].

Zinc has a specific role as an antioxidant and an immune modulator and possibly has a direct antiviral effect [5]. It is a micronutrient of key interest in efforts at curtailing the morbidity and mortality of HIV infection [6]. Low serum zinc has been reported in Ugandan HIV infected children [7]. At present, the zinc status of HAART naive HIV infected children in Nigeria is unknown.
Vitamin C is the major water-soluble antioxidant and acts as the first defence against the tissue-damaging reactive oxygen species produced during infections [8]. Prevalent vitamin $\mathrm{C}$ deficiency has been observed in an earlier study on HIV infected adolescents [9]. Vitamin C has therefore become a key component of various micronutrient supplementation studies in HIV infected children [10-12].

Both selenium [13] and zinc [14] are bound to albumin for their transportation within the plasma. Hypoalbuminemia therefore causes low serum levels of selenium and zinc, though the total body content may still be normal. In malnourished HIV infected patients, their serum albumin level should be taken into account and controlled for before conclusions are drawn regarding the serum selenium and zinc concentrations.

A recent Cochrane review [15] has identified three micronutrients (selenium, zinc, and vitamin D) as having a huge potential for reducing HIV related morbidity and mortality. Formulation of a supplementation programme relevant to our population will require knowledge of the micronutrient 
status of HIV infected children in our population as micronutrient needs vary widely across diverse regional settings [16]. Most of the pre-HAART micronutrient studies in the literature relate to adults. The few that were done in children either lacked HIV negative controls $[6,17]$ or had a relatively small sample size [18]. Furthermore, there is a lack of data on micronutrient status of HIV infected children in Nigeria. A case-controlled study in Nigeria on micronutrient levels of HIV infected children will therefore be of great relevance.

The objective of the study was to determine the serum levels of zinc, selenium, and vitamin $\mathrm{C}$ in $\mathrm{HIV}$ infected children in Obafemi Awolowo University Teaching Hospitals Complex (OAUTHC), Ile-Ife, as well as the relationship to disease severity and nutritional status.

\section{Materials and Methods}

The study was conducted at the paediatric consultant outpatient clinic of the Ife Hospital Unit (IHU) of the OAUTHC IleIfe, Osun State, Nigeria. The IHU is a three hundred bedded tertiary health facility located about a hundred and sixty kilometres northeast of Lagos.

Although, the paediatric HIV clinic started in 1997, there were no free drugs for treatment until in 2005 when OAUTHC was included in the National Antiretroviral Treatment Rollout Programme. The hospital also receives referrals and transfers of patients from all the southwestern states and beyond. Over three hundred HIV infected and exposed children are seen in the clinics monthly. The hospital serves as the first port of call for most of the referred, transferred, and newly identified HIV infected children. HIV negative general paediatric cases are seen simultaneously as well. The latter group was the major source of the study controls aside from other paediatric related clinics such as paediatric orthopaedic and paediatric surgery clinics.

The study was a hospital-based, cross-sectional, descriptive, and case control study. All consecutive newly identified HIV infected children over 18 months of age were eligible for recruitment into the study. Patients were excluded from the study when there was (a) lack of consent from the child's care giver, (b) any on-going febrile illness, diarrhoea, or history suggestive of tuberculosis or liver disease such as hepatitis, and (c) on-going supplement usage at the time of the study or within the month preceding it, and (d) when subjects were on antiretroviral therapy $[20,21]$.

The study commenced in August 2007 and ended in January 2009. A total of 70 HIV infected children were recruited. Each of them was age and sex matched with a HIV negative apparently healthy child as the control. Thus a total number of 140 children (subjects and controls) were recruited into the study.

An ethical clearance certificate was obtained from the Research and Ethical Committee of the OAUTHC before the study was commenced.

2.1. Data Collection. All recruited subjects and controls were interviewed by the investigator according to the study proforma to determine their age, tribe, and address. The socioeconomic status was also ascertained according to Oyedeji social classification method [19]. The World Health Organization revised clinical staging was used to stage each HIV infected subject [22]. Weights and heights were measured according to standard methods [23]. Each measurement was taken twice by the investigators assisted by resident doctors, after which the mean was recorded. Pretest and posttest counselling were offered to all of the patients in compliance with the WHO guidelines on provider-initiated testing and counselling (PITC) [24]. HIV screening was done in the haematology laboratory of the OAUTHC by rapid testing using the parallel method according to the national algorithm of HIV testing in use at that time [25]. The two test kits were Determine $^{\mathrm{R}}$ HIV-1/2 (Abbot Laboratories, Japan) and Chembio HIV 1/2 STAT-PAK, (Chembio Diagnostic System Inc. New York, USA). Afterwards, subjects as well as controls were offered posttest counselling and then recruited into the study if they granted consent. Subjects and controls were nonfasting and the blood samples were collected in the morning (i.e. before 12 noon). This was then shared as follows: four millilitres dispensed into plain specimen tube while the two millilitres was emptied into ethylenediaminetetraacetic acid (EDTA) bottles. The samples in the plain tube were left still in a cool corner, protected from light, to allow for sufficient clotting and retraction. This process took less than four hours after which they were then spun with a centrifuge at 3,000 revolutions per minute for 10 minutes. The serum was thereafter separated with a bulb pipette. Two millilitres of serum was usually derived. Half millilitre was sent to the OAUTHC Chemical Pathology Laboratory for albumin while the rest was immediately kept in a laboratory freezer at $-20^{\circ} \mathrm{C}$ until analysis for the micronutrients.

2.2. Sample Analysis. Zinc and selenium were analysed at the Central Science Laboratory of Obafemi Awolowo University, Ile-Ife, with a flame atomic absorption spectrophotometer (model 210) manufactured by Buck Scientific Corporation, Connecticut, USA. The Nigerian Food Consumption Survey of 2003 [26] used $80 \mu \mathrm{g} / \mathrm{dL}$ as the lowest limit of normal for zinc. Values lower than $80 \mu \mathrm{g} / \mathrm{dL}$ were taken to indicate zinc deficiency in this study. For serum selenium, values less than $85 \mathrm{mg} / \mathrm{L}$ are generally defined as deficient [27]. Vitamin C concentration was also measured by spectrophotometry using 2, 4-dinitrophenylhydrazine as a chromogen [28]. For the analysis of vitamin C, the Roe's method [29] was used. Essentially, plasma specimen was diluted with metaphosphoric acid to produce a protein-free filtrate which was then stored at $-20^{\circ} \mathrm{C}$. Analysis was done in batches within 2 weeks after sample collection as that is the maximum period for which ascorbate stability is guaranteed at that storage temperature [30]. In a recent study in Nigeria, $0.5 \mathrm{mg} / \mathrm{dL}$ was the lower limit of normal for plasma ascorbic acid [31] and this value was used as the cutoff for vitamin $\mathrm{C}$ deficiency in this study.

2.3. Statistical Analysis. SPSS Statistical Software Package (SPSS version 11.0, SPSS Inc. Chicago, Ill, USA) was used for the data entry. Results are expressed as means \pm SD. Means were compared using student's $t$-test while the categorical 
variables were compared using the Pearson Chi squared tests. $Z$-scores of the anthropometric measurements were calculated using the Epi lnfo statistical software package (EPI INFO version 7.0. CDC, 2011) based on WHO Child Growth Standards and WHO Reference 2007. $P$ values $<0.05$ were regarded as significant. Pearson correlation analysis was also done to determine significant direct or inverse relationships between continuous variables. Linear regression analysis was subsequently done to identify predictors of micronutrient status among social class, body mass index, clinical stage, and immunological stages while controlling for age, gender, and albumin levels which are possible confounders.

\section{Results}

3.1. The Study Population and General Sociodemographics. Over the period of study, there were a total of 2057 new cases seen at the clinics of the paediatric consultant outpatient department. A hundred and nine (5.3\%) of them were HIV infected. Thirty nine of the HIV infected patients were excluded from the study mainly on grounds of acute illness at presentation (25), age less than eighteen months (11), and HAART usage (3). The study population therefore comprised $70 \mathrm{HIV}$ infected children (subjects) as well as $70 \mathrm{HIV}$ negative children who served as controls. The age range of the subjects and control was the same (24 to 180 months). The gender ratio was similar in both subjects and control $(\mathrm{M}: \mathrm{F}=1: 1.3$; $P=0.87$ ). Table 1 shows the demographic, clinical, and micronutrient data of the studied subjects and controls. There were more of the infected children in the lower socioeconomic class compared to the controls and the difference was statistically significant $(P=0.005)$.

3.2. Nutritional Status and HIV Infection Stages. More of the infected children were stunted, wasted, and underweight compared to the controls $(P=0.001)$ (Table 1). Forty (57.1\%) of the infected subjects were hypoalbuminaemic compared to $7(14.9 \%)$ of the control $(P=0.001)$. Table 1 also demonstrates the distribution of the HIV infected patients according to their WHO clinical and immunological stages. Forty seven (67.1\%) subjects were in the late clinical stages (stages 3 and 4) while $51(72.9 \%)$ presented with remarkable immunosuppression (severe and advanced).

3.3. Serum Micronutrients. Table 1 shows that the differences between the mean zinc, selenium, and vitamin $C$ levels of subjects and the corresponding values for the controls were all statistically significant $(P=0.001)$. The percentage of HIV infected children who were deficient in each of the micronutrients was greater when compared to the controls. These differences were statistically significant $(P=0.001)$. Among the HIV infected subjects, 41 (58.6\%) were deficient in all of the three micronutrients while 49 (70\%) were deficient in both zinc and selenium.

3.4. Relationship between Serum Micronutrient Levels and WHO Clinical Stages, Immunological Categories, Nutritional Status, and Serum Albumin. Figures 1, 2, and 3 depict the

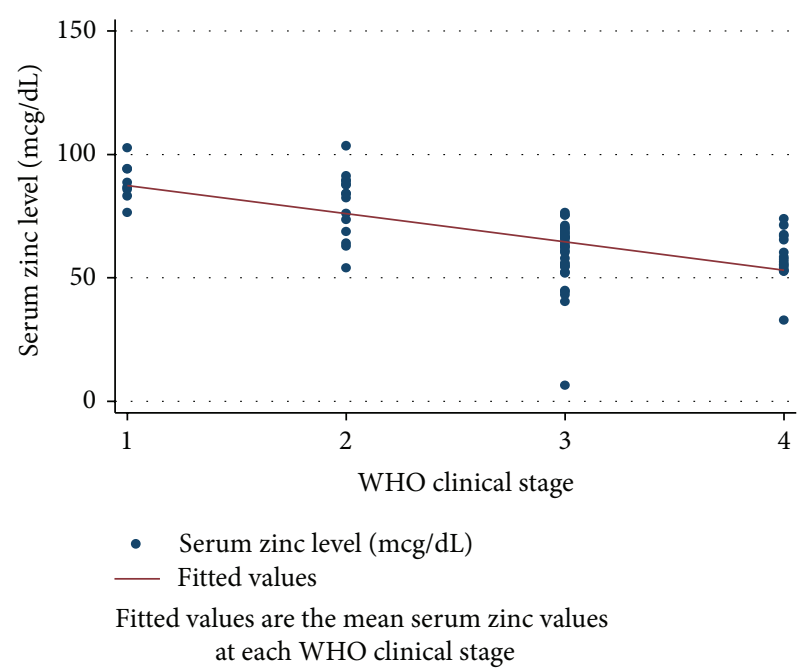

FIgURE 1: The relationship between Serum zinc levels and clinical stage of HIV infected subjects.

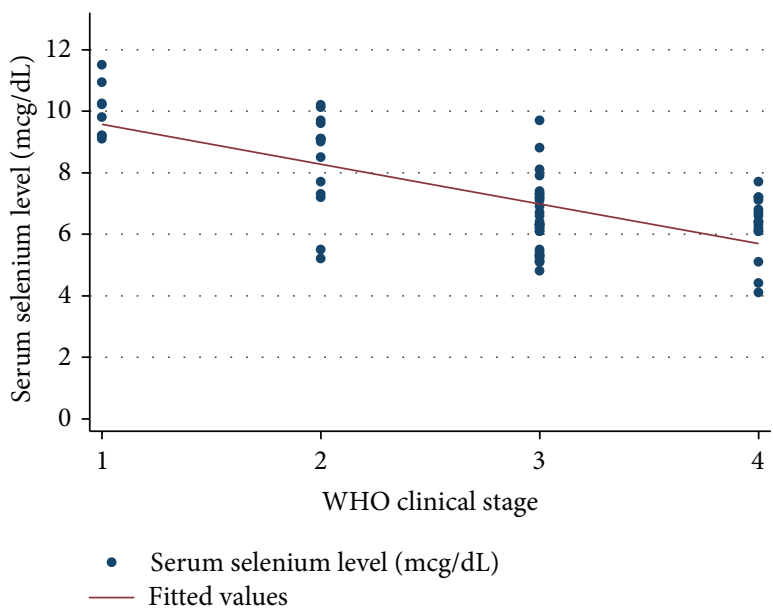

Fitted values are the mean serum selenium values at each WHO clinical stage

Figure 2: The relationship between serum selenium levels and clinical stage of HIV infected subjects.

progressive decrease in serum zinc, selenium, and vitamin $\mathrm{C}$ level with deteriorating clinical stage. Table 2 shows the mean serum micronutrient level at various categories of immunosuppression. With both of the categorization methods employed, the mean serum micronutrient levels between early and late categories were significantly different across the three micronutrients. The weight-for-age $z$-scores were higher in HIV infected subjects who had normal serum zinc, selenium, and vitamin C levels than in those who were deficient in any of the 3 micronutrients. There was significant positive correlation between serum albumin and the serum level of each of the micronutrients $(r=0.386, P=0.001 ; r=$ $0.466, P=0.001$; and $r=0.377, P=0.001$ for zinc, selenium, and vitamin C, resp.) (Table 3). This prompted a further linear 
TABLE 1: Demographic, clinical, and micronutrient data of HIV infected subjects and the HIV negative controls.

\begin{tabular}{|c|c|c|}
\hline Variables & Infected $[N=70]$ & Control $[N=70]$ \\
\hline Age range (mths) & 24-180 & $24-180$ \\
\hline \multicolumn{3}{|l|}{ Age group } \\
\hline $18-59$ mths $(n, \%)$ & $43(61.4)$ & $43(61.4)$ \\
\hline $60-119$ mths $(n, \%)$ & $21(30.0)$ & $22(31.4)$ \\
\hline $120-227$ mths $(n, \%)$ & $6(8.6)$ & $5(7.1)$ \\
\hline Mean age \pm SD (mths) & $58.4 \pm 37.8$ & $58.01 \pm 38.1$ \\
\hline Gender $(\mathrm{M}$ versus $\mathrm{F})$ & 40 versus 30 & 39 versus 31 \\
\hline \multicolumn{3}{|l|}{${ }^{*}$ Social class $(n, \%)$} \\
\hline I & - & 9 (112.9) \\
\hline II & $14(20.0)$ & $19(27.1)$ \\
\hline III & $16(22.9)$ & $15(21.4)$ \\
\hline${ }^{\#} \mathrm{IV}$ & $27(38.9)$ & $13(18.6)$ \\
\hline $\mathrm{V}$ & $13(18.6)$ & $14(20.0)$ \\
\hline \multicolumn{3}{|l|}{ Anthropometry $Z$ scores } \\
\hline${ }^{\#}$ Median WAZ $(25,75)$ male & $-0.18(-0.62,0.59)$ & $-0.35(-0.54,0.38)$ \\
\hline Median WAZ $(25,75)$ female & $-0.53(-0.81,0.36)$ & $-0.51(-0.66,-0.15)$ \\
\hline Median $\operatorname{HAZ}(25,75)$ male & $-0.13(-0.67,0.70)$ & $-0.22(0.68,0.79)$ \\
\hline Median $\operatorname{HAZ}(25,75)$ female & $-0.61(-0.88,0.46)$ & $-0.53(-0.83,0.18)$ \\
\hline${ }^{\#}$ Median WHZ $(25,75)$ male & $-1.34(-2.29,-0.21)$ & $-0.34(-0.89,0.09)$ \\
\hline${ }^{\#}$ Median WHZ $(25,75)$ female & $-1.13(-1.87,-0.44)$ & $-0.32(-1.11,0.00)$ \\
\hline${ }^{\#}$ Mean \pm SD serum albumin $(\mathrm{g} / \mathrm{L})$ & $3.2 \pm 0.7$ & $4.0 \pm 0.5$ \\
\hline${ }^{\#}$ Mean \pm SD CD 4 count (cells $\left./ \mathrm{mL}\right)$ & $611.4 \pm 444.5$ & $1388.2 \pm 556.5$ \\
\hline${ }^{\#}$ Mean \pm SD CD4 \% (\%) & $18.8 \pm 13.2$ & $35.4 \pm 4.4$ \\
\hline \multicolumn{3}{|l|}{ Clinical stage $(n, \%)$} \\
\hline 1 & $8(11.4)$ & - \\
\hline 2 & $15(21.4)$ & - \\
\hline 3 & $31(44.3)$ & - \\
\hline 4 & $16(22.9)$ & - \\
\hline \multicolumn{3}{|l|}{ Immunological stage $[n(\%)]$} \\
\hline Not significant immunosuppression & $4(5.7)$ & - \\
\hline Mild significant immunosuppression & $15(21.4)$ & - \\
\hline Advanced significant immunosuppression & $18(25.7)$ & - \\
\hline Severe significant immunosuppression & $33(47.1)$ & - \\
\hline \multicolumn{3}{|l|}{ Serum micronutrient $($ mean $\pm \mathrm{SD})$} \\
\hline${ }^{\#} \operatorname{Zinc}(\mu \mathrm{g} / \mathrm{dL})$ & $66.99 \pm 16.7$ & $82.78 \pm 25.8$ \\
\hline${ }^{\#}$ Vitamin $\mathrm{C}(\mu \mathrm{g} / \mathrm{dL})$ & $0.41 \pm 0.29$ & $0.78 \pm 0.28$ \\
\hline${ }^{\#}$ Selenium $(\mu \mathrm{g} / \mathrm{dL})$ & $7.26 \pm 0.2$ & $9.81 \pm 1.6$ \\
\hline Low albumin $[n(\%)]$ & $40(57.1)$ & $7(14.9)$ \\
\hline \multicolumn{3}{|l|}{ Micronutrient deficiency $[n(\%)]$} \\
\hline${ }^{\#}$ Zinc deficient & $54(77.1)$ & $31(44.3)$ \\
\hline${ }^{\#}$ Selenium deficient & $50(71.4)$ & $13(18.6)$ \\
\hline${ }^{\#}$ Vitamin C deficient & $49(70.0)$ & $11(15.7)$ \\
\hline
\end{tabular}

${ }^{*}$ By Oyedeji [19]. ${ }^{*} P<0.05$.

regression analysis in which the concentration of albumin was controlled for.

3.5. Regression Analysis. With serum selenium, zinc, and vitamin $\mathrm{C}$ as the dependent variables, regression analysis was done for each of them to determine if social class, BMI, clinical, and immunological stages were predictors of each micronutrient serum levels while controlling for age, sex, and the other biochemical parameters which are potential confounders. The clinical stages as well as the advanced and severe immunosuppression categories were discovered to be significant predictors of serum selenium, serum zinc, and to a lesser extent, vitamin C. Interestingly, for all the micronutrients studied, it was found that as the clinical stages increased 
TABLE 2: Relationship between the mean serum micronutrient levels and CD4 categories of the HIV infected subjects.

\begin{tabular}{|c|c|c|c|c|c|c|c|}
\hline & $N$ & Selenium $($ mean \pm SD $)$ & $P$ & Zinc $($ mean $\pm S D)$ & $P$ & Vitamin $C($ mean \pm SD $)$ & \\
\hline $\mathrm{CD} 4<350$ & 25 & $6.11 \pm 1.09$ & \multirow{2}{*}{0.0001} & $58.70 \pm 16.53$ & \multirow{2}{*}{0.002} & $0.34 \pm 0.15$ & \multirow{2}{*}{0.005} \\
\hline $\mathrm{CD} 4 \geq 350$ & 45 & $7.97 \pm 1.67$ & & $71.99 \pm 15.07$ & & $0.46 \pm 0.18$ & \\
\hline $\mathrm{CD} 4<25 \%$ & 61 & $6.93 \pm 1.53$ & \multirow{2}{*}{0.0001} & $64.52 \pm 16.0$ & \multirow{2}{*}{0.001} & $0.39 \pm 0.17$ & \multirow{2}{*}{0.014} \\
\hline CD4 $\geq 25 \%$ & 9 & $9.52 \pm 1.34$ & & $83.69 \pm 11.53$ & & $0.57 \pm 0.18$ & \\
\hline
\end{tabular}

$N$ is the number of infected HIV subjects in that CD4 category.

$P$ is significant at $<0.05$.

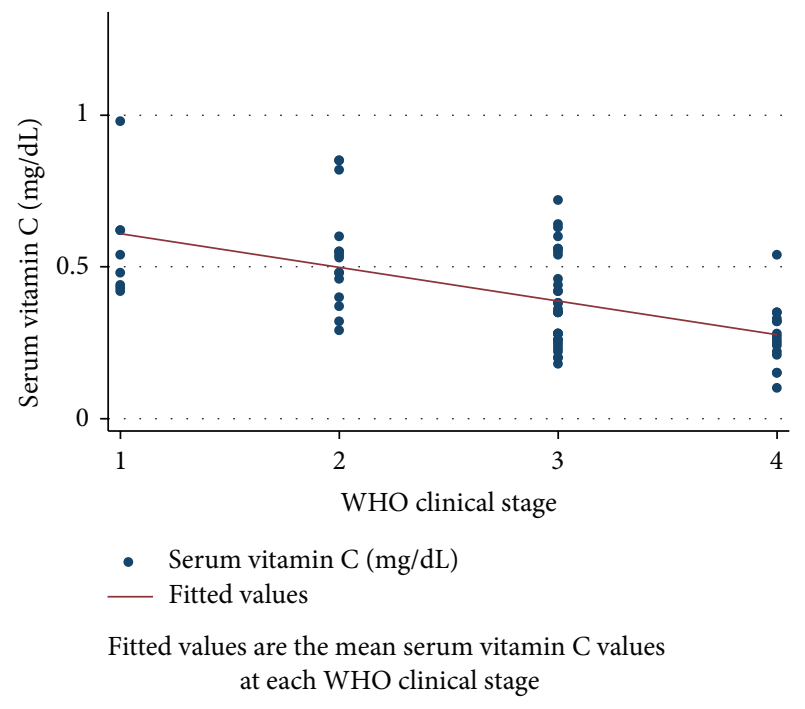

FIGURE 3: The relationship between serum vitamin C levels and clinical stage of HIV infected subjects.

(to stages 3 and then 4 ), the regression coefficients further reduced, and the reduction was significant as well $(P<0.05)$. (Table 4).

\section{Discussion}

The significantly low levels of zinc and selenium in HIV infected subjects are similar to findings in developing countries $[3,6,18]$ as well as developed countries $[2,32]$. Zinc is required by HIV to form enzymes such as viral integrase, which plays a key role in its replication [6]. Prevalence of deficiency among HAART naive HIV infected children ranges from $32 \%$ among Rwandan children [33] to $100 \%$ among Thai children [17]. Our prevalence of $77.1 \%$ falls between these. Regional disparity in the zinc intake as well as nonexclusion of children on micronutrient supplements in some of the other studies may account for the difference. Related to this higher prevalence of serum zinc deficiency in HIV infected children is the significantly lower mean of serum zinc level in HIV infected subjects as compared to the controls. In this study, the serum zinc level depreciates progressively as the disease stage worsens. This was evident in the significant direct trend between serum zinc level and increasing clinical stage (Table 4 and Figure 1) as well as between serum zinc level and degree of immunosuppression (Table 4).
TABLE 3: Correlation of albumin with serum micronutrients level in HIV infected subjects.

\begin{tabular}{cccc}
\hline & $\begin{array}{c}\text { Albumin versus } \\
\text { zinc }\end{array}$ & $\begin{array}{c}\text { Albumin versus } \\
\text { selenium }\end{array}$ & $\begin{array}{c}\text { Albumin versus } \\
\text { vitamin C }\end{array}$ \\
\hline$r$ & 0.386 & 0.466 & 0.377 \\
$P$ & 0.001 & 0.001 & 0.001 \\
$N$ & 70 & 70 & 70 \\
\hline
\end{tabular}

$N$ : number of HIV infected subjects.

$r$ : correlation coefficient.

$P$ is significant $<0.05$.

As the virus proliferates, the serum level of zinc reduces, perhaps due to its utilization by the virus as well as the body defence systems. A similar finding was found in other studies in children and adults $[6,17,33,34]$. A significant percentage (57.1\%) of the HIV infected patients had hypoalbuminaemia. Similar finding was also observed in Cape Town where $70 \%$ of the HAART naive HIV infected children were hypoalbuminaemic. This is to be expected as albumin, apart from being an indicator of nutritional status, is also a negative acute phase protein [35]. In this study, albumin levels had a significant positive correlation with serum zinc level (Table 3). Albumin is known to transport at least $60 \%$ of zinc in the plasma [14]. The possibility then exists that the low serum zinc could be a result of the hypoalbuminaemia and not a true decrease in zinc level. However, when the level of albumin was controlled for in a linear regression model, the serum zinc levels particularly in clinical stages 3 and 4 as well as all levels of immunosuppression reduced significantly as the disease worsened.

The prevalence of selenium deficiency among HIV infected children in this study was $71.4 \%$ and it is higher than the range of $0 \%$ to $37 \%$ seen in literature $[2,17,33]$. The selenium level in the soil and common foods in these areas may contribute to the observed differences. Serum selenium was also demonstrated in this study, just like in some others $[2,3]$, to reduce in HIV infected patients as the disease worsened clinically (Table 4 and Figure 2). This is thought to result from its utilization by the body to produce glutathione peroxidase [2], an antioxidant that counteracts the prooxidant activity of HIV. This study found a statistically significant difference between mean selenium levels of infected subjects and controls (Table 1). Albumin level showed a significant positive correlation with selenium levels (Table 3 ). This is not surprising, as $17-32 \%$ of serum selenium is bound to albumin [14]. In this study, a linear regression model that controlled for the 
TABLE 4: Predictors of serum selenium, zinc, and vitamin C in HIV infected subjects.

\begin{tabular}{|c|c|c|c|c|c|c|}
\hline \multirow{2}{*}{ Predictor ${ }^{\#}$} & \multicolumn{2}{|c|}{ Selenium } & \multicolumn{2}{|l|}{ Zinc } & \multicolumn{2}{|l|}{ Vitamin C } \\
\hline & Coefficient (CI) & $P$ & Coefficient (CI) & $P$ & Coefficient (CI) & $P$ \\
\hline Social class 2 & $0.91(-0.12,1.93)$ & 0.08 & $0.30(-9.00,9.61)$ & 0.95 & $0.07(-0.06,0.21)$ & 0.28 \\
\hline Social class 4 & $0.36(-0.61,1.33)$ & 0.46 & $6.71(-3.19,16.61)$ & 0.18 & $0.02(-0.11,0.15)$ & 0.72 \\
\hline Social class 3 & $0.73(-0.08,1.55)$ & 0.08 & $4.71(-4.15,13.33)$ & 0.29 & $0.06(-0.05,0.17)$ & 0.25 \\
\hline Social class 5 & $0(-1.00,1.00)$ & 1.00 & $-0.22(-11.06,10.63)$ & 0.97 & $0(-0.14,0.14)$ & 1.0 \\
\hline BMI & $-0.82(-0.29,0.13)$ & 0.43 & $0.09(-2.14,2.32)$ & 0.08 & $-0.00(-0.03,0.02)$ & 0.87 \\
\hline Clinical stage 2 & $-1.52(-2.66,0.37)$ & $0.01^{*}$ & $-11.02(-23.33,1.29)$ & 0.94 & $-0.01(-0.16,0.14)$ & 0.87 \\
\hline Clinical stage 3 & $-3.59(-4.73,-2.45)$ & $<0.001^{*}$ & $-29.12(-41.50,-16.74)$ & $0.001^{*}$ & $-0.18(-0.33,-0.03)$ & $0.02^{*}$ \\
\hline Clinical stage 4 & $-3.70(-5.02,-239)$ & $<0.001^{*}$ & $-30.64(-45.85,-15.45)$ & $0.001^{*}$ & $-0.28(-0.45,-0.10)$ & $0.002^{*}$ \\
\hline Mild immunosuppression & $-0.40(01.64,0.84)$ & 0.52 & $-1.52(-16.31,13.27)$ & $0.01^{*}$ & $-0.20(-0.37,-0.02)$ & $0.03^{*}$ \\
\hline Advanced immunosuppression & $-3.10(-4.45,-1.95)$ & $<0.001^{*}$ & $-18.63(-32.72,-4.55)$ & $0.001^{*}$ & $-0.35(-0.51,-0.18)$ & $0.001^{*}$ \\
\hline Severe immunosuppression & $-3.20(-4.28,-1.91)$ & $<0.001^{*}$ & $-25.05(-39.90,-10.21)$ & $0.001^{*}$ & $-0.39(-0.56,-0.22)$ & $0.001^{*}$ \\
\hline
\end{tabular}

\#Social class 1, Clinical stage 1, and insignificant immunosuppression results were the references.

${ }^{*} P$ values were significant $(P<0.05)$.

The test of linearity and influential points proved the fit of the regression model.

level of serum albumin portrayed that the serum selenium in HIV infected patients had a significant negative correlation with disease progression (Table 4).

Serum vitamin $C$ in this study was also significantly lower in infected children than in the controls (Table 1). The prevalence of vitamin $\mathrm{C}$ deficiency was also significantly higher in infected subjects than in controls. These are similar to findings from other studies [9]. The antioxidant role of vitamin $\mathrm{C}$ in combating the prooxidant activity of HIV infection is believed to be largely responsible for vitamin C deficiency in HIV infection. In a linear regression model, serum vitamin $\mathrm{C}$ levels in HIV infected patients displayed a significant negative regression coefficient which reduced as the clinical stage increased (Table 3).

The prevalence of multiple-micronutrient deficiency was also similar to the observation in Cape Town [18] where 62\% of the children had two or more micronutrient deficiencies. In our study, $70 \%$ of the children were deficient in both zinc and selenium with $58.6 \%$ being deficient in the three micronutrients. This knowledge will be of immense benefit as micronutrient mixtures for supplementation trial are being contemplated.

This study found HIV infected children to be generally of lower socioeconomic status compared to the HIV negative controls (Table 1). HIV prevalence is generally higher among low socioeconomic status [36]. The higher incidence among children of lower socioeconomic background has been attributed to a lower access to prevention of mother to child transmission services due to associated illiteracy, lower awareness, and poverty [37]. The observation in this study that HIV infected children had lower nutritional indices than the HIV negative controls (Table 1) has been reported in other studies $[38,39]$ which attributed the finding partially to poor food intake and the catabolic effects of the opportunistic infections.

It was observed that the children that had the least weight for age z-scores in this study were the HIV infected children who were also deficient in either zinc or selenium. This agrees with the Ugandan study [5] which found a positive correlation between zinc and undernutrition. A recent study found an increase of $0.3(0.04-0.56)$ in mean weight-forage z-scores among HIV infected children six months after supplementation with multiple micronutrient supplements that contained zinc [40].

We consider, as a limitation to this study, our inability to assess the dietary intake of micronutrients simultaneously with serum levels. Hence, the influence of poor intake may not be separated from the impact of the HIV itself on micronutrient status. The study being cross-sectional would also not prove causality.

In conclusion, there is prevalent deficiency in the serum levels of zinc, selenium, and vitamin C in apparently stable, ambulant, HAART naïve HIV infected children in Ile-Ife, South western Nigeria. Of significant importance is the huge percentage of multiple-micronutrient deficiency. These deficiencies are associated with low weight for age z-scores in these children. The serum levels of zinc and selenium decline as the clinical stage of HIV infection worsens with severe clinical and immunological stages being significant predictors of selenium, zinc, and vitamin C status. Socioeconomic class does not predict the serum levels of zinc, selenium, and vitamin C in HIV infected children. These findings may be a guide on the choice of the category of subjects and the outcome measures as well as the micronutrient components of supplements that would be formulated in future controlled supplementation trials in these children.

\section{Conflict of Interests}

The authors declare that there is no conflict of interests regarding the publication of this paper.

\section{References}

[1] WHO Global monitoring framework and strategy for the global plan towards the elimination of new HIV infections among 
children by 2015 and keeping their mothers alive (EMTCT), April 2012.

[2] C. B. Stephensen, G. S. Marquis, S. D. Douglas, L. A. Kruzich, and C. M. Wilson, "Glutathione, glutathione peroxidase, and selenium status in HIV-positive and HIV-negative adolescents and young adults," The American Journal of Clinical Nutrition, vol. 85, no. 1, pp. 173-181, 2007.

[3] P. S. Ogunro, T. O. Ogungbamigbe, P. O. Elemie, B. E. Egbewale, and T. A. Adewole, "Plasma selenium concentration and glutathione peroxidase activity in HIV-1/AIDS infected patients: a correlation with the disease progression," Nigerian Postgraduate Medical Journal, vol. 13, no. 1, pp. 1-5, 2006.

[4] R. Kupka, M. Garland, G. Msamanga, D. Spiegelman, D. Hunter, and W. Fawzi, "Selenium status, pregnancy outcomes, and mother-to-child transmission of HIV-1," Journal of Acquired Immune Deficiency Syndromes, vol. 39, no. 2, pp. 203-210, 2005.

[5] J. P. Allard, E. Aghdassi, J. Chau, I. Salit, and S. Walmsley, "Oxidative stress and plasma antioxidant micronutrients in with HIV infection," American Journal of Clinical Nutrition, vol. 67, no. 1, pp. 143-147, 1998.

[6] R. Bobat, H. Coovadia, C. Stephen et al., "Safety and efficacy of zinc supplementation for children with HIV-1 infection in South Africa: a randomised double-blind placebo-controlled trial," The Lancet, vol. 366, no. 9500, pp. 1862-1867, 2005.

[7] G. Ndeezi, J. K. Tumwine, B. J. Bolann, C. M. Ndugwa, and T. Tylleskär, "Zinc status in HIV infected Ugandan children aged 1-5 years: a cross sectional baseline survey," BMC Pediatrics, vol. 10 , article 68, 2010.

[8] B. Frei, L. England, and B. N. Ames, "Ascorbate is an outstanding antioxidant in human blood plasma," Proceedings of the National Academy of Sciences of the United States of America, vol. 86, pp. 6377-6381, 1989.

[9] C. B. Stephensen, G. S. Marquis, R. A. Jacob, L. A. Kruzich, S. D. Douglas, and C. M. Wilson, "Vitamins $\mathrm{C}$ and $\mathrm{E}$ in adolescents and young adults with HIV infection," The American Journal of Clinical Nutrition, vol. 83, no. 4, pp. 870-879, 2006.

[10] S. Mda, J. M. A. van Raaij, F. P. R. de Villiers, U. E. MacIntyre, and F. J. Kok, "Short-term micronutrient supplementation reduces the duration of pneumonia and diarrheal episodes in HIV-infected children," Journal of Nutrition, vol. 140, no. 5, pp. 969-974, 2010.

[11] G. Ndeezi, T. Tylleskär, C. M. Ndugwa, and J. K. Tumwine, "Effect of multiple micronutrient supplementation on survival of HIV-infected children in Uganda: a randomized, controlled trial," Journal of the International AIDS Society, vol. 13, no. 1, article 18, 2010.

[12] S. Mda, J. M. van Raaij, F. P. de Villiers, and F. J. Kok, "Impact of multi-micronutrient supplementation on growth and morbidity of HIV-infected South African children," Nutrients, vol. 5, no. 10, pp. 4079-4092, 2013.

[13] I. Harrison, D. Littlejohn, and G. S. Fell, "Distribution of selenium in human blood plasma and serum," Analyst, vol. 121, no. 2, pp. 189-194, 1996.

[14] P. K. Drain, J. M. Baeten, J. Overbaugh et al., "Low serum albumin and the acute phase response predict low serum selenium in HIV-1 infected women," BMC Infectious Diseases, vol. 6, article 85, 2006.

[15] J. H. Irlam, N. Siegfried, M. E. Visser, and N. C. Rollins, "Micronutrient supplementation for children with HIV infection," Cochrane Database of Systematic Reviews, 2013.
[16] H. Friis, Micronutrients and HIV Infection: A Review of Current Evidence, World Health Organisation, Durban, South Africa, 2005.

[17] B. Torsak, U. Sasiwimol, H. Rawiwan, K. Pope, N. Chaiwat, and K. Suparat, "Correlation of selenium and zinc levels to antiretroviral treatment outcomes in Thai HIV-infected children without severe HIV symptoms," European Journal of Clinical Nutrition, vol. 66, no. 8, pp. 900-905, 2012.

[18] B. S. Eley, A. A. Sive, L. Abelse, G. Kossew, M. Cooper, and G. D. Hussey, "Growth and micronutrient disturbances in stable, HIV-infected children in Cape Town," Annals of Tropical Paediatrics, vol. 22, no. 1, pp. 19-23, 2002.

[19] G. A. Oyedeji, "Socioeconomic and cultural background of hospitalised children in Ilesha," Nigerian Journal of Paediatrics, vol. 12, article 11, 1985.

[20] A. M. Tang, J. Lanzillotti, K. Hendricks et al., "Micronutrients: current issues for HIV care providers," AIDS, vol. 19, no. 9, pp. 847-861, 2005.

[21] B. Amare, K. Tafess, F. Ota et al., "Serum concentration of selenium in diarrheic patients with and without HIV/AIDS in Gondar, Northwest Ethiopia," Journal of AIDS and Clinical Research, vol. 2, no. 6, 2011.

[22] WHO, Antiretroviral Therapy for HIV Infection in Infants and Children: Towards Universal Access Recommendations for Public Health Approach, World Health Organisation, Geneva, Switzerland, 2006.

[23] A. R. Frisancho, Anthropometric Standards for the Assessment of Growth and Nutritional Status, The University of Michgan Press, Ann Arbor, Mich, USA, 1990.

[24] UNAIDS/WHO, Guidance on Provider-Initiated HIV Testing and Counselling in Health Facilities, UNAIDS and World Health Organization, Geneva, Switzerland, 2007.

[25] Federal Ministry of Health, "HIV-1 syphilis seroprevalence and STD syndromes sentinel survey among PTB and STD patients in Nigeria," Tech. Rep., Federal Ministry of Health, Abuja, Nigeria, 2001.

[26] B. Maziya-Dixon, I. O. Akinyele, E. B. Oguntona, S. Nokoe, R. A. Sanusi, and E. Harris, Nigeria Food Consumption and Nutrition Survey 2001-2003, International Institute of Tropical Agriculture (IITA), 2004.

[27] D. Behne, “Selenium," Annales Nestle, vol. 52, no. 3, pp. 107-117, 1994.

[28] A. Kaplan, I. L. Szabo, and L. E. Ophenn, Clinical Chemistry: Interpretation and Techniques, Lea and Fabeger, Interpretation and Techniques. Lea and Fabeger, 3rd edition, 1998.

[29] J. H. Roe and C. A. Keuther, "The determination of ascorbic acid in whole blood and urine through the 2,4-dinitrophenylhydrazine," The Journal of Biological Chemistry, vol. 147, pp. 399407,1943

[30] M. Zahoor-ul-Hassan Dogar, M. Salman Akhtar, S. Siddique Ansir, and M. Shoaib Akhtar, "Comparison of three different spectrophotometric methods for determination of Vitamin C levels in human body fluid," Journal of Applied Pharmacy, vol. 3, no. 2, pp. 67-71, 2010.

[31] H. N. Ene-Obong, I. F. Odoh, and O. E. Ikwuagwu, "Plasma vitamin $\mathrm{A}$ and $\mathrm{C}$ status of in-school adolescents and associated factors in Enugu State, Nigeria," Journal of Health Population and Nutrition, vol. 21, no. 1, pp. 18-25, 2003.

[32] B. E. Hurwitz, J. R. Klaus, M. M. Llabre et al., "Suppression of human immunodeficiency virus type 1 viral load with selenium supplementation: a randomized controlled trial," Archives of Internal Medicine, vol. 167, no. 2, pp. 148-154, 2007. 
[33] F. Ndagije, C. Baribwira, and J. B. S. Coulter, "Micronutrients and T-cell subsets: a comparison between HIV-infected and uninfected, severely malnourished Rwandan children," Annals of Tropical Paediatrics, vol. 27, no. 4, pp. 269-275, 2007.

[34] M. E. Visser, G. Maartens, G. Kossew, and G. D. Hussey, "Plasma vitamin A and zinc levels in HIV-infected adults in Cape Town, South Africa," British Journal of Nutrition, vol. 89, no. 4, pp. 475482, 2003.

[35] C. Gabay and I. Kushner, "Acute-phase proteins and other systemic responses to inflammation," The New England Journal of Medicine, vol. 340, no. 6, pp. 448-454, 1999.

[36] J. G. Fortson, "The gradient in sub-saharan Africa: socioeconomic status and HIV/AIDS," Demography, vol. 45, no. 2, pp. 303-322, 2008.

[37] S. A. Jones, G. G. Sherman, and C. A. Varga, "Exploring socioeconomic conditions and poor follow-up rates of HIV-exposed infants in Johannesburg, South Africa," AIDS Care, vol. 17, no. 4, pp. 466-470, 2005.

[38] M. A. Magadi, "Household and community HIV/AIDS status and child malnutrition in sub-Saharan Africa: evidence from the demographic and health surveys," Social Science and Medicine, vol. 73, no. 3, pp. 436-446, 2011.

[39] E. W. Kimani-Murage, S. A. Norris, J. M. Pettifor et al., "Nutritional status and HIV in rural South African children," BMC Pediatrics, vol. 11, article 23, 2011.

[40] S. Mda, J. M. A. van Raaij, U. E. MacIntyre, F. P. R. de Villiers, and F. J. Kok, "Improved appetite after multi-micronutrient supplementation for six months in HIV-infected South African children," Appetite, vol. 54, no. 1, pp. 150-155, 2010. 


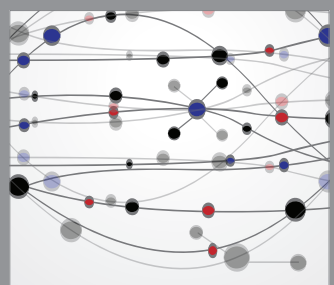

The Scientific World Journal
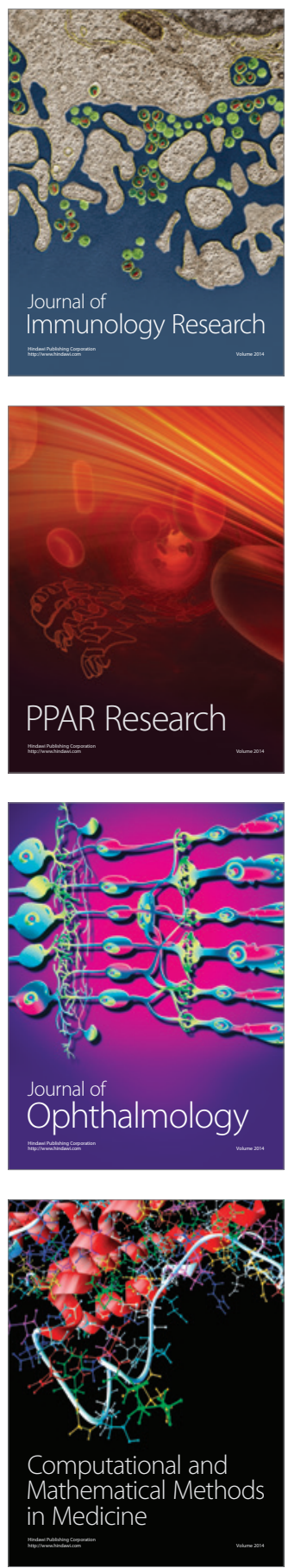

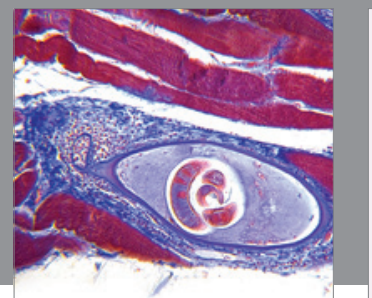

Gastroenterology

Research and Practice
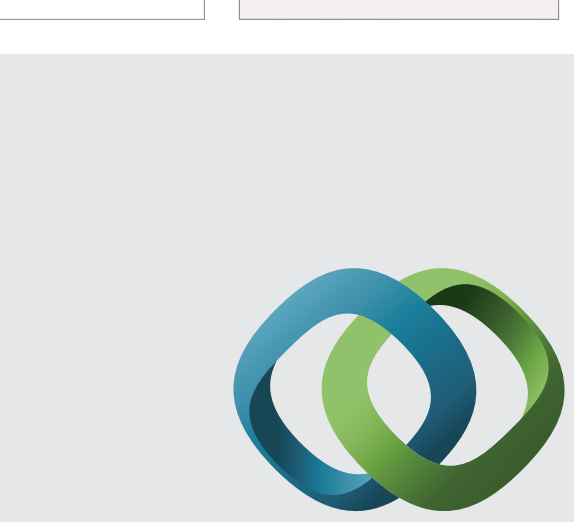

\section{Hindawi}

Submit your manuscripts at

http://www.hindawi.com
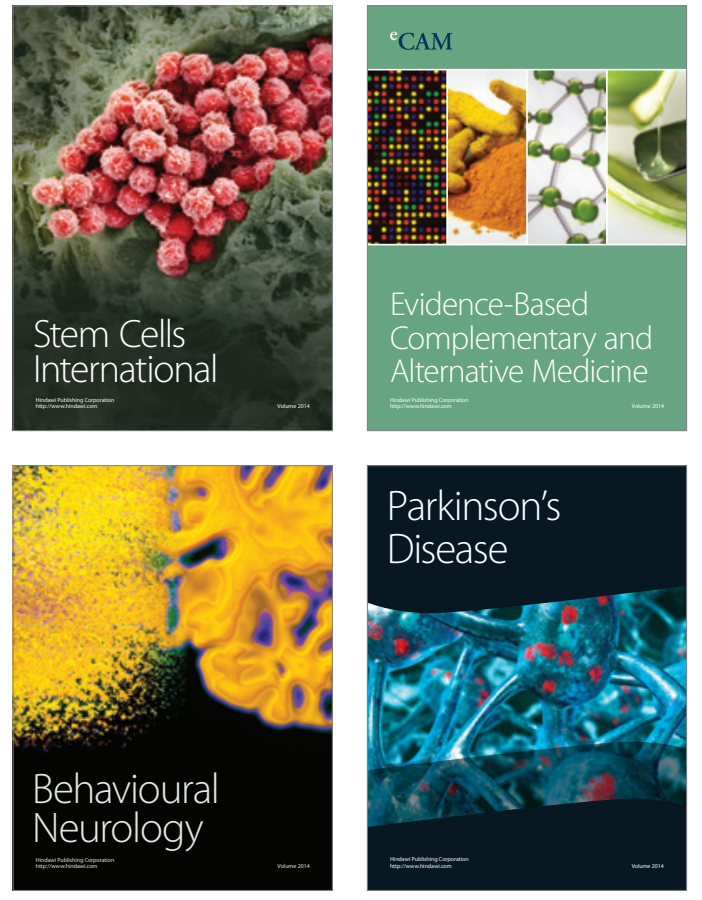
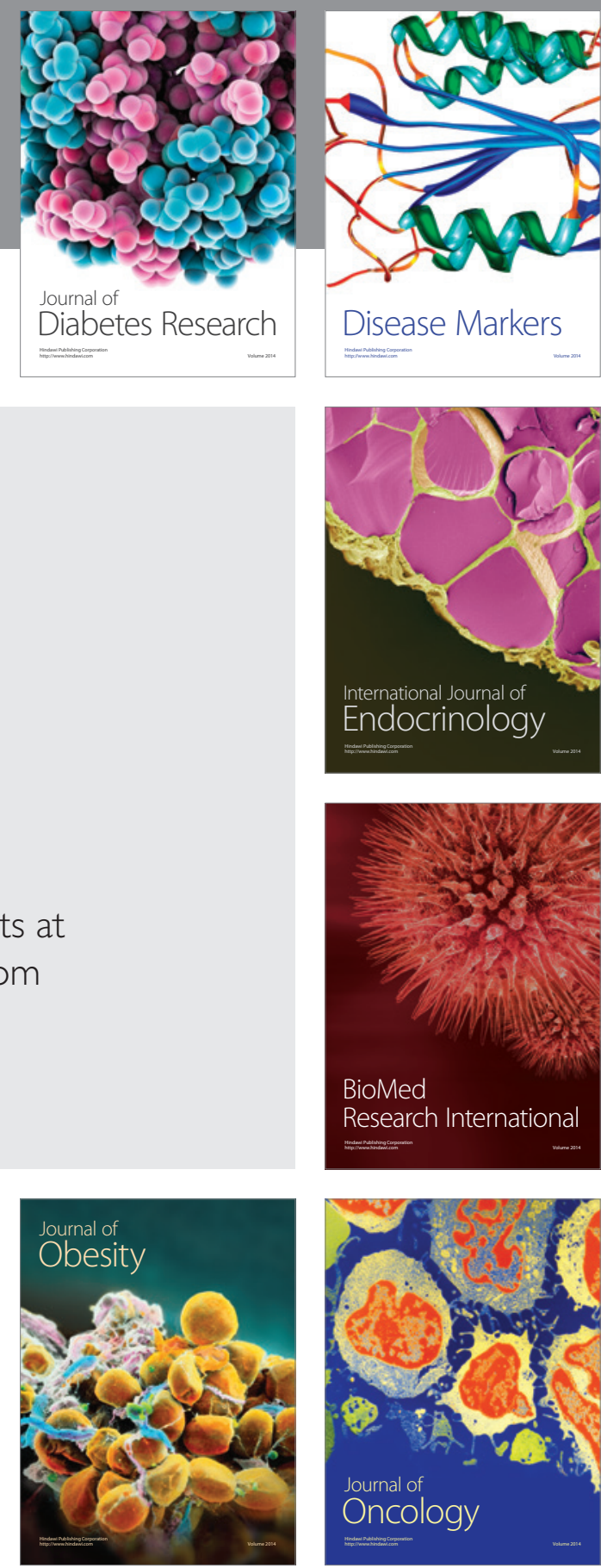

Disease Markers
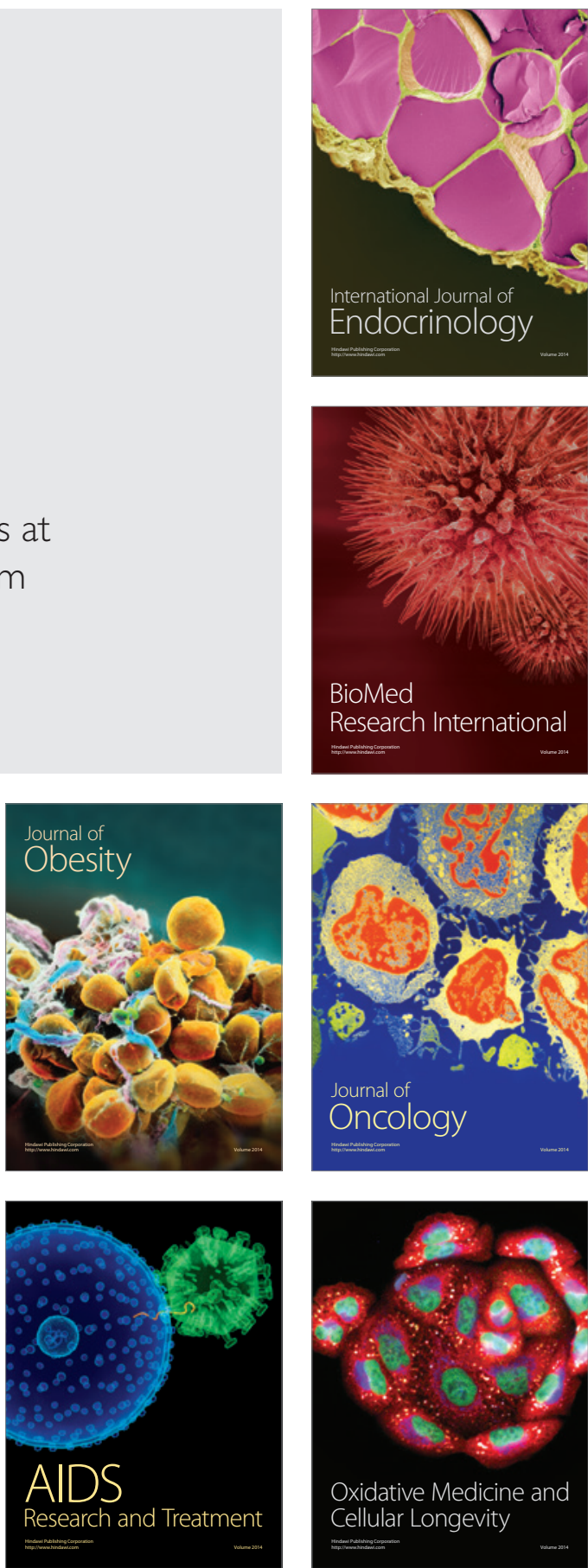